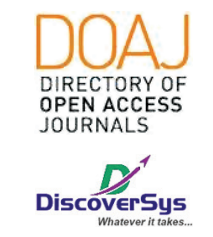

Published by DiscoverSys

\section{The effect of femoral head size on volumetric wear rate following total hip joint replacement surgery}

\author{
Jason Rahmadi Ruslie*
}

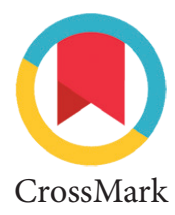

CrossMark

\title{
ABSTRACT
}

Background: Numerous data records that the number of total hip joint replacement is increasing in many parts of the world which also indicates an increase demand for total hip joint replacement and revision surgery. The purpose of this paper is to review the literature regarding the size of femoral head and its relation to the volumetric wear rate of the polyethylene lining of the hip's acetabular component.

Methods: A systematic literature search performed to identify relevant publications for this review in five databases: University of Melbourne Science, Medline/ Pubmed, Cochrane Library, and Ebsco. The search was completed on 6 0ctober 2012 and again on 24 October 2012. The following keywords and phrases were used: total hip joint replacement, femoral head size, wear, polyethylene and arthroplasty.
Results: The six studies are all prospective cohort studies with a follow-up time ranging between three to ten years at the minimum. One study conducted by Hammerberg et al. did not mention the minimum length of their follow up however they include a mean follow up period which is 3.6 years. Two studies did not mention the number of patients they are following up. Every other studies mention how many participants included in their study, but these two studies mention how many hips undergo the total hip joint replacement surgery. The number of patients mentioned in the studies vary from the minimum of 42 patients up until 200 patients. The number of hips in each study ranged from 45 hips to 385 hips.

Conclusion: This review concludes that the use of larger femoral head size hastens the wear rate of the polyethylene lining of the acetabulum component.
Faculty of Medicine of Indonesia University
${ }^{*}$ Correspondence to: Jason Rahmadi Ruslie, Faculty of Medicine of Indonesia University jason_ruslie@hotmail.com

Received: 2019-01-27 Accepted: 2019-04-17 Published: 2019-08-01

Keywords: femoral head, volumetric wear rate, total hip replacement Cite the Article: Ruslie, J.R. 2019. The effect of femoral head size on volumetric wear rate following total hip joint replacement surgery. Intisari Sains Medis 10(2): 347-353. D0I: 10.15562/ism.v10i2.403

\section{INTRODUCTION}

Numerous data records that the number of total hip joint replacement is increasing in many parts of the world ${ }^{1-5}$ which also indicates an increased demand for total hip joint replacement and revision surgery. In a study conducted by Williams et al., out of 7,806 patients above 65 years old that undergo a primary total hip joint replacement as high as $13 \%$ from the whole sample need a revision hip joint replacement surgery. ${ }^{6,7}$ From the increase in demand, an increasing prevalence on total hip joint replacement surgery can be seen, and this also is an indicator of increasing potential demand for revision surgical procedures.

New Zealand reported 12 years data from January 1999 to December 2010. During those 12 years, it recorded that there were 71,057 primary hip procedures registered including 1,093 resurfacing arthroplasties. Not to mention an additional 7,378 to primary hip procedures from last year's report. ${ }^{1}$

In 2010, 76,759 hip replacement procedures were recorded on the National Joint Registry (NJR), a British joint department annual report, indicating a $6 \%$ increase in comparison to their report on the previous year. The number mentioned is made up of 68,907 primary hip replacements and 7,852 revision surgeries. This number on revision surgery shows an increase of 649 in comparison to 2009. The revision ratio in 2010 is $11 \%{ }^{2}$

In the history of the Australian National Joint Replacement Registry, they recorded 332,351 hip replacements up until December 2011. It would be an additional 38,022 hip procedures if the figure from last year's report were added. They record a total of $71.8 \%$ primary total hip replacement and as high as $12.1 \%$ revision hip replacement. ${ }^{3}$

During 2010 the number of primary hip arthroplasties in Sweden continued to increase. Compared with the previous year when the number rose from 14,456 to $15,736(+8.9 \%)$, the 2010 increase to 15,935 is more modest $(+1.3 \%)$. Compared with 2000, the number of primary arthroplasties increased by $41 \% .{ }^{4}$

The Canadian Joint Replacement Registry reported 16,613 hip replacement in 2001-2002 and 2,081 revision surgery, a revision surgery ratio of $11.1 \%$ in one year. ${ }^{5}$

The rate of revision surgery of hip replacement is also a significant thing to point out. Most revisions recorded by the Australian Orthopedic Registry 
are major revisions $(84.8 \%)$. The most common types of revision are acetabular only (32.4\%), THR (femoral/acetabular) (29.8\%) and femoral only $(17.6 \%) .^{3}$ The high number of revision surgery indicates that large amount of money are allocated to revise the hip replacement surgery, especially in the acetabular component. If surgeons and other medical staff can minimize the high prevalence of revision surgery, the costs savings could be used for other beneficial things.

This topic is important not only due to the high number of cases worldwide, but it also had raised some controversial issues regarding the relationship between the size of the femoral head and the wear rate of the acetabular polyethylene lining. This controversy continue to develop between surgeons on which method provides the best result for their patients. Lachiewicz et al. and Livermore et al. suggested that bigger femoral head can decrease the incidence of dislocation however it may also increases the wear rate of the polyethylene lining. It stated that the volume of debris from wear and the rate of volumetric wear for $32 \mathrm{~mm}$ head were significantly higher than for those with $22 \mathrm{~mm}$ to $28 \mathrm{~mm}$ femoral heads. ${ }^{89}$ Another journal article stated that both small and large femoral heads does not make any daily clinical practice significant difference. ${ }^{10,11}$ This theory was further agreed by Muragtoglu et al. that uses a simulated gait movement study and Sayeed et al. that suggested there are no correlation between the femoral head size when articulating with thick and thin polyethylene lining. ${ }^{12,13}$ This systematic review will focus on the relationship between the femoral head and the wear rate of polyethylene lining of the acetabular component rather than the relationship between the size of femoral head and incident of post-operative dislocation/prosthesis failure.

The major cause of doing a hip replacement revision surgery is aseptic loosening, followed by dislocation of the joint. ${ }^{1-5}$ From all the patient that undergoes a total hip joint replacement surgery, approximately, one-third of these patient suffers recurrent dislocations and consequently require revision surgery. The annual cost caused by dislocation are estimated to be at least $\$ 75$ million in the United States alone. ${ }^{14-18}$ Studies has proven that bigger femoral head may decrease incidence of post-operative dislocations. Emerging evidence suggests that a more massive femoral head may lead to earlier polyethylene wear of the acetabular liner which is a cause for failure and revision of the hip replacement surgery. Thus, while a larger femoral head reduces one problem, it may be creating another. ${ }^{13}$

In spite of the presence of research evidence comparing the femoral head size with polyethylene lining, controversy persists regarding which of these results are true about the relationship between the femoral head size and the volumetric wear of the polyethylene lining. The purpose of this paper is to review the literature regarding the size of femoral head and its relation to the volumetric wear rate of the polyethylene lining of the hip's acetabular component. In addition to those points mentioned above, the identification of the optimum femoral head size essentialness will also be reviewed. This finding is important not only because of the high prevalence of total hip joint replacement surgery, but it may also provide recommendations to guide surgeons and other medical staffs in making the right decision for the patient in the future.

\section{METHODS}

A systematic literature search were performed to identify relevant publications for this review in five databases: University of Melbourne Library catalog, Web of Science, Medline / Pubmed, Cochrane Library, and Ebsco. The search was completed on 6 October 2012 and again on 24 October 2012. The following keywords and phrases were used: total hip joint replacement, femoral head size, wear, polyethylene and arthroplasty. Moreover, the systematic search were expanded manually to find potentially relevant articles by screening reference lists of all included articles. Titles and abstracts of all the studies were scanned to ensure that they fulfilled the inclusion and exclusion criteria. If the abstract was imprecise, the full text was read before the selection decision was made.

Studies were included in the review if they fulfilled all of the following inclusion criteria: 1) the study investigated the association between the femoral head size to the volumetric or general wear of the polyethylene lining; 2) the article was written in English; 3) the article was a full-text article. Studies were excluded to be appraised in the systematic review if they met the following exclusion criteria: 1) those with less than 20 participants; 2) those with less than two years follow up period; 3) not using human subjects as the sample of their study. The following information was extracted from the included studies: (1) General information about the article including Author, year of publication, institution, start date, end date, number of patients, sex, age, age range, type of study and follow up period. (2) Patient's characteristics. (3) Outcome measures and comparison parameters between a smaller femoral head with the larger one and the clinical outcome of both. (4) Time at which follow-up measurements were conducted. (5) Results of the studies, including measures of variability of the data. 
All eligible studies in this systematic review were assessed using the Preferred Reporting Items for Systematic reviews and Meta-Analysis (PRISMA). It is an evidence-based minimum set of items for reporting in systematic reviews and meta-analyses. The aim of the PRISMA Statement is to help authors improve the reporting of systematic reviews and meta-analyses. PRISMA focuses on ways in which authors can ensure a transparent and complete reporting of this type of research. PRISMA has mainly focused on systematic reviews and meta-analysis of randomized control trial studies, but it can also be used as a basis for reporting reviews of other types of research such as observational studies. PRISMA may also be useful for critical appraisal of published systematic reviews, although it is not a quality assessment instrument to gauge the quality of a systematic review. The PRISMA Statement consists of a 27 -item checklist and a four-phase flow diagram. The 27 checklist items pertain to the content of a systematic review and meta-analysis, which include the title, abstract, methods, results, discussion, and funding. The flow diagram depicts the flow of information through the different phases of a systematic review. It maps out the number of records identified, included and excluded, and the reasons for exclusions. ${ }^{19}$

\section{RESULTS}

\section{Literature search}

First literature yielded 219 potentially relevant articles. Out of these, a total of 68 studies were retrieved from the title review. From the remaining 68 articles, 37 articles were excluded in general review. Out of the 31 articles for full-text review, ten did not have the full-text article. After reviewing the full-text articles, 13 studies did not meet the inclusion criteria. Therefore it leaves us with eight articles, which consisted of 6 articles to be discuss and 2 articles for supporting articles. The 2 supporting articles were not critically appraised in this review because Sayeed et al did their study with different thickness of the polyethylene lining (thick and thin polyethylene lining) and not the size of the femoral heads. The second study conducted by Muratoglu et al. was a simulation study using a simulated environment of a large femoral head size with the wear rate of the polyethylene lining and not using a human subject.

\section{Study characteristics}

The six studies are all prospective cohort studies with a follow-up time ranging between three to ten years at the minimum. One study conducted by Hammerberg et al. did not mention the minimum length of their follow up however they include a mean follow up period which is 3.6 years. ${ }^{20}$ There are two studies that did not mention the number of patients they are following up. Those studies are Livermore et al. and Lachiewicz et al. ${ }^{8,9}$

Every other studies mention how many participants included in their study, but these two studies just mention how many hips undergo the total hip joint replacement surgery. The number of patients mentioned in the studies vary from the minimum of 42 patients up until 200 patients. The number of hips in each study ranged from 45 hips to 385 hips. The study conducted by Geller et $\mathrm{a}^{10}$ had the least number of participants/hips replacement surgery compared to other studies. They only had 42 patients with only 45 hips and this is a fairly small sample number compared with the others. A description of all the studies is presented in table 1.

Table 1 Study characteristics

\begin{tabular}{|c|c|c|c|c|c|}
\hline Author (Year) & Design & $\mathbf{N}$ & Follow up Period & Exposure & Outcome \\
\hline Livermore (1990) & $\begin{array}{l}\text { Prospective } \\
\text { cohort study }\end{array}$ & 385 hips & At least 9.5 years & $\begin{array}{l}22 \mathrm{~mm}, 28 \mathrm{~mm}, \\
32 \mathrm{~mm}\end{array}$ & $\begin{array}{l}32 \mathrm{~mm} \text { has greater volumetric wear } \\
\text { than } 22 \mathrm{~mm} \& 28 \mathrm{~mm}\end{array}$ \\
\hline Geller (2006) & $\begin{array}{l}\text { Prospective } \\
\text { cohort study }\end{array}$ & 42 patients, 45 hips & At least 3 years & $\begin{array}{l}36 \mathrm{~mm}, 38 \mathrm{~mm}, \\
40 \mathrm{~mm}\end{array}$ & No correlation \\
\hline Bragdon (2007) & $\begin{array}{l}\text { Prospective } \\
\text { cohort study }\end{array}$ & 182 patients, 200 hips & At least six years & $\begin{array}{l}26 \mathrm{~mm}, 28 \mathrm{~mm} \\
32 \mathrm{~mm}, 38 \mathrm{~mm}\end{array}$ & No correlation \\
\hline Lachiewiczs (2009) & $\begin{array}{l}\text { Prospective } \\
\text { cohort study }\end{array}$ & 145 hips & $5-8$ years & $\begin{array}{l}26 \mathrm{~mm}, 28 \mathrm{~mm}, \\
32 \mathrm{~mm}, 36 \mathrm{~mm}, \\
40 \mathrm{~mm}\end{array}$ & $\begin{array}{l}\text { Greater volumetric wear with the } \\
36 \mathrm{~mm} \& 40 \mathrm{~mm}\end{array}$ \\
\hline Hammerberg (2010) & $\begin{array}{l}\text { Prospective } \\
\text { cohort study }\end{array}$ & 70 patients, 80 hips & Mean: 3.6 years & $\begin{array}{l}28 \mathrm{~mm}, 32 \mathrm{~mm}, \\
38 \mathrm{~mm}, 40 \mathrm{~mm}\end{array}$ & $\begin{array}{l}\text { Volumetric wear was } 12.4 \mathrm{~mm} 3 / \mathrm{y} \\
\text { higher with bigger heads }\end{array}$ \\
\hline Shaju (2005) & $\begin{array}{l}\text { Prospective } \\
\text { cohort study }\end{array}$ & 117 patients, 138 hips & At least ten years & $22 \mathrm{~mm}, 32 \mathrm{~mm}$ & $\begin{array}{l}\text { Radiographic acetabular loosening } \\
\text { was associated with increased } \\
\text { volumetric wear of the } 32-\mathrm{mm} \\
\text { acetabular components }(\mathrm{P}<0.0001) \text {. }\end{array}$ \\
\hline
\end{tabular}


The variability of the patients characteristics (inclusion and exclusion criteria) and their approach of each studies are quite broad. Livermore et al. did not mention the age range and mean of their patients however they state that there are no statistically significant differences among groups about the ages of the patients. They also did not mention the preoperative diagnosis of their patients, but again, they state that there are no statistically significant differences among groups. To determine whether there was an association between the patient's weight and the result, they divided the patients into three groups by body weight (less than $63,63-68$, more than 68 kilograms). They reviewed a total of 385 hips (no number of patients included) with 227 hips in $22 \mathrm{~mm}, 98$ in $28 \mathrm{~mm}$, and 60 in $32 \mathrm{~mm}$ femoral head. ${ }^{9}$

Lachiewics et al. patients mean age is 61,1 years old with a range of 27-87 years of age. They also include the mean Body Mass Index for their study which is 29 , ranges from 18,9-46,4 kilograms / $\mathrm{m}^{2}$. Preoperative diagnoses of their patients are osteoarthritis in 65 hips, osteonecrosis in 20 hips, rheumatoid arthritis in 5 hips, and other etiology in 12 hips. All procedures are using a posterior approach. Lachiewics et al. used five different sizes of femoral head. They have 14 hips in $26 \mathrm{~mm}, 33$ hips in $28 \mathrm{~mm}$, 35 in $32 \mathrm{~mm}$, and five hips in $40 \mathrm{~mm}$ femoral heads. ${ }^{8}$

Another study conducted by Geller et al. stated their average age of their patients is 62,5 years which ranges between 28-86. They used three femoral head sizes which are $36 \mathrm{~mm}$ for 24 hips, $38 \mathrm{~mm}$ for 16 hips, and $40 \mathrm{~mm}$ femoral head for only five hips. Their preoperative diagnoses of their patients are end-stage degenerative joint disease. They include 22 females and 20 males in their study. Majority of the hips (43 hips), undergo a posterolateral Kocher - Langenbeck approach while two hips using anterolateral approach. ${ }^{10}$

Bragdon et al. include as many as 182 patients (200 hips) in their study which includes 91 females and 109 males. The mean age of the patients is 60,1 years old which ranges between 22-90 years of age. They have two hips in the $26 \mathrm{~mm}, 100$ hips in $28 \mathrm{~mm}$, 94 hips in $32 \mathrm{~mm}$, and four hips in the $38 \mathrm{~mm}$ group. However, they did not mention any of the patient's condition, preoperative diagnoses of their patients and the surgical approach they used. ${ }^{11}$ Bragdon et al. is the only study that did not use the term 'volumetric wear'. They just mentioned about general wear, not volumetric wear in specific.

Shaju et al. conducted their study with a total of 117 patients (138 hips). They have 65 patients (78 hip) in the $22 \mathrm{~mm}$ group and the other 52 patients (60 hips) in the $32 \mathrm{~mm}$ head size group. All their patients were being treated with a posterior surgical approach. They did not mention the patient's condition and preoperative diagnoses of their patients. ${ }^{21}$

The last study to be discussed was conducted by Hammerberg et al. This study include 70 patients (80 hips) in their study. Their preoperative diagnoses for their patients were osteoarthritis in 68 hips, avascular necrosis in 6 hips, traumatic osteoarthritis in 5 hips, and one hip had rheumatoid arthritis. The average age of their patients are 65,1 years old (ranges between 39-89 years old). All their patients were also treated with a posterior surgical approach. ${ }^{20}$

\section{Exposure measure}

All the studies included in the review used radiographic measurement and clinically assessment to determine the total amount of the volumetric wear in each size of femoral heads. However, they use different approach on the radiographs and the scoring in the clinical assessment.

Livermore et al. used anteroposterior radiograph on the hips. The reliability of the radiographic technique was confirmed by correlating the measurements with actual measurements of wear from retrieved implants. Since the time of implantation, 12 of the 385 polyethylene acetabular components had been replaced because of aseptic loosening. Direct measurements of these components were correlated with the measurements on the most recent radiograph before revision. Livermore et al. also used the formula $V=\pi r^{2} w$. V symbolizes the volumetric wear; $r$ is the radius of the femoral head; $\mathrm{w}$ is the measured linear migration of the head through the polyethylene. ${ }^{9}$

Lachiewicz et al. used the same approach as Livermore et al. on the radiograph measurement, but they also used the frog-lateral radiograph. Total volumetric wear and volumetric wear rates were calculated using custom equations based on the two-dimensional wear magnitude, femoral bearing size, and the direction of wear concerning the face of the polyethylene liner. The linear and volumetric wear data were analyzed using a specific multivariate analysis. ${ }^{8}$

Another study which is conducted by Geller et al. used a similar approach of radiograph measurement. In this study, they used anteroposterior view of the pelvis centered over the pubis, frog lateral views of the hip, and a shoot through lateral of the hip. For clinical assessment tools, they used several types of scoring. Those are Harris Hip Score, UCLA score, Western Ontario and McMaster University Osteoarthritis Index (WOMAC) score, and a SF-36 functional score. ${ }^{10}$

Similar approach was also done in the study conducted by Bragdon et al. Sequential radiographic examinations included an anteroposterior 
view of the pelvis centered over the pubis, anteroposterior and frog lateral views of the involved hip, and a shoot-through lateral of the hip. Not only that, but they also used the similar clinical assessment tools like Geller et al. which are the Harris Hip Score, UCLA activity score, and the WOMAC score. ${ }^{11}$

Shaju et al. outcomes was measured radiographically by a single observer on anteroposterior $\mathrm{x}$-rays of the pelvis. For clinical assessment, they used two scoring which are Harris Hip Score and Charnley's Functional Grading. Furthermore, Shaju et al. adopt the formula given by Livermore et al. which is $\mathrm{V}=\pi \mathrm{r}^{2} \mathrm{w} .{ }^{21}$

The last study conducted by Hammerberg et al. used a supine anteroposterior pelvic radiograph, and a Lowenstein lateral radiograph were made preoperatively and postoperatively at clinic follow-up visits. They used Harris Hip Score and testing the range of motion of their patients to assess the clinical outcome.

\section{Study outcomes}

Livermore et $\mathrm{al}^{9}$ found that the $32 \mathrm{~mm}$ group had a significantly greater average volume and rate of volumetric wear than either the $22 \mathrm{~mm}$ or the $28 \mathrm{~mm}$ group $(\mathrm{p}<0.001)$. Lachiewics et al. found that there was a greater volumetric wear as much as $156,6 \mathrm{~mm}^{3}$ per year with the $36 \mathrm{~mm}-40 \mathrm{~mm}$ femoral heads. Shaju et al. stated that the mean rate of linear wear was higher in the 22-mm femoral head, whereas the volumetric wear was higher in the $32-\mathrm{mm}$ femoral head. Hammerberg et al. found that volumetric wear was approximately $12.4 \mathrm{~mm}^{3} /$ year higher with bigger heads.

Two studies conducted by Geller et al. and Bragdon et al. stated that there were no correlation between the femoral head size and the volumetric wear. Geller et $\mathrm{al}^{10}$ found that the wear of highly cross-linked polyethylene is very low, even with large diameter femoral heads. Bragdon et $\mathrm{al}^{11}$ stated that there were no correlation between the total wear rate and age, gender, primary diagnosis, surgical approach, brand of polyethylene, femoral head size, mode of femoral stem fixation, use of trochanteric osteotomy, UCLA activity score, Harris hip score, or WOMAC scores.

\section{DISCUSSION}

\section{Outcomes}

Four out of six studies observed a significant association between larger femoral head size to increased volumetric wear rate. Livermore et $\mathrm{al}^{9}$ found that the $32 \mathrm{~mm}$ group had a significantly greater average volume and rate of volumetric wear than either the $22 \mathrm{~mm}$ or the $28 \mathrm{~mm}$ group $(\mathrm{p}<0.001)$. Moreover, they stated very clearly that "the greatest volumetric wear and mean rate of volumetric wear were seen with $42 \mathrm{~mm}(\mathrm{P}<0.001)$ ". They also stated that the association of greater body weight with increasing volumetric wear was significant. However, long wear was not significantly associated with body weight. Lachiewicz et $\mathrm{al}^{8}$ share the same result as Livermore et al. Lachiewics et al. found that there was a greater volumetric wear as much as $156,6 \mathrm{~mm}^{3}$ per year with the $36 \mathrm{~mm}-40 \mathrm{~mm}$ femoral heads. They observed no difference $(\mathrm{p}<0.598)$ between femoral head size and the mean linear wear rate but found a difference between femoral head size and the mean volumetric wear rate $(\mathrm{p}<0.0005)$ and the mean total volumetric wear $(\mathrm{p}<0.0131)$. There was less $(p<0.0056)$ total volumetric wear in the 32-mm head group compared with that in the 36- and 40-mm head group but not between the 26- $\mathrm{mm}$ and $28-\mathrm{mm}$ groups compared with that in the 36 - and $40-\mathrm{mm}$ head group. Shaju et al ${ }^{21}$ with a mutual outcome to the previous studies stated that The mean rate of linear wear was higher in the $22-\mathrm{mm}$ femoral head, whereas the volumetric wear was higher in the $32-\mathrm{mm}$ femoral head. They also found out that radiographic acetabular loosening was associated with increased volumetric wear of the $32-\mathrm{mm}$ acetabular components $(\mathrm{P}<0.001)$. Shaju et al. came out with a conclusion that larger femoral head sizes are theoretically associated with greater stability of the joint but also with greater frictional torque at the acetabular bone-cement interface, creating an increase in volumetric wear of the polyethylene lining. Their data show that the volumes of debris from wear and the rate of volumetric wear of $32 \mathrm{~mm}$ head were significantly greater than those for the $22 \mathrm{~mm}$ head. Another study that draw a similar conclusion to the studies above is conducted by Hammerberg et al. ${ }^{20}$ They found that volumetric wear was approximately $12.4 \mathrm{~mm}^{3} /$ year higher with bigger heads. The volumetric wear for small head group was $16.7 \pm$ $8.2 \mathrm{~mm}^{3} /$ year (range, 4.3-54.6), whereas, for the large head group, it was almost double at $29.1 \pm$ $14.8 \mathrm{~mm}^{3} /$ year (range, 8.4-112.8).

Not all of the studies came out with the same conclusion. Two studies conducted by Geller et al. and Bragdon et al. stated that there were no correlation between the size of the femoral head and the volumetric wear rate. Geller et $\mathrm{al}^{10}$ found that the data strongly suggest that the wear of highly crosslinked polyethylene is very low, even with large diameter femoral heads (no significant outcome between the smaller and larger heads). This conclusion is further supported by Bragdon et al who stated very clearly that there were no correlation between 
the total wear rate and age, gender, primary diagnosis, surgical approach, brand of polyethylene, femoral head size, mode of femoral stem fixation, use of trochanteric osteotomy, UCLA activity score, Harris hip score, or WOMAC scores.

\section{General limitations}

Almost all studies did not use any inclusion and exclusion criteria. They include every patient that undergo a total hip joint replacement surgery. However, an inclusion criteria was made by one study conducted by Geller et al. They include patient at "high risk" for post-operative dislocation, and those are avascular necrosis (AVN) secondary to alcohol abuse, neurological disorder, advanced age, or personality traits suspicious for noncompliance in obeying hip precautions. ${ }^{10,22}$ An exclusion criteria was also made by one study conducted by Shaju et al. Patients who had undergone revision surgery for symptomatic aseptic loosening of components were not included in the study. ${ }^{21}$

Some of the limitations of this review is that all of the six studies that were discussed were all prospective cohort studies. Non of the studies are randomized control trial. Another limitation of this review is that each of the studies discussed used different sizes of femoral heads. It makes us difficult to create a conclusion with the variability of the method used by each studies.

\section{Methodology limitations}

There are a wide variability in methods and their limitations. Geller et al. used only 42 subjects (45 hips) in their study which is quite a small sample size for a study. They also only do a minimum of 3 years follow up to their patients. Furthermore, Geller et al. used $36 \mathrm{~mm}, 38 \mathrm{~mm}$, and a $40 \mathrm{~mm}$ femoral head size. This is a limitation because all of those sizes are considered as a large head. In other words, Geller et al. did not compare the large femoral head size with the small one, and this may be the reason why their result shows no correlation between the femoral head size and the volumetric wear. Bragdon et al. stated their drawbacks and one of them was that they do not have a comparison group of patients with a large diameter femoral head articulating against conventional UHMWPE while other studies have. ${ }^{11}$ Lachiewics et al. state that their study limitation is that it is not randomized. ${ }^{8}$ Not only that, they also said that they did not routinely have their patients to complete a validated activity scale (which may be associated with the wear rate). Also, 25 hips (17\%) of the original cohort were lost to follow-up, and these could have included patients with high or low wear rates. Shaju et al. used only two types of femoral head size, and it is quite hard to see the significance between the femoral head sizes and volumetric wear if the comparison is only using two sizes of heads. The last study conducted by Hammerberg et al. have some limitations. The first one is the short follow-up period which have a mean of 3,6 years. A second limitation is that only one type of highly cross-linked polyethylene was tested. The third limitation would be that range of motion testing was done manually and

not with a jig that would give the most accurate comparison. The fourth limitation is that limitation is that the activity levels are subjectively graded from the patientss description of their capability. There could be variations in activity level that could only be measured objectively using a pedometer and the number of step cycles the patient takes.

\section{Implication to Practice}

Choosing the suitable femoral head size for the patients remained a preference of the surgeon who are doing the operation. However, smaller femoral head size are proven to have higher dislocation incidence than the larger ones. The studies reviewed conclude that bigger femoral head size may increase the volumetric wear rate of the polyethylene lining. Nevertheless, there is still not enough evidence to say that using larger heads are better than using the smaller one. Furthermore, the studies in his review have different methodologies such as variability on the femoral head size used. The big variability in the method used by each studies make us very difficult to make a clear conclusion from the results. Also, some of the studies used $22 \mathrm{~mm}$ head size which is rarely used in clinical practice. Thus, we cannot use and apply their result to clinical practice since it is uncommonly used.

\section{Further improvements}

One of the improvements in the future that can be made is by using a larger sample size. By doing so, the outcome of the research is more valid than those who are using a smaller sample size. Secondly, in studying the relationship between the femoral head size and the wear rate of the polyethylene lining, the study has to have a more extended period when they are following up the patient. This is very important because adverse effects or other clinical outcomes may not appear in the first 2 4 years. They are more likely to appear in long term period (6 - 10 years). Another improvement that can be made in the future is that researchers should undertake more randomized control trials studies with a stated inclusion and exclusion criteria rather than conducting cohort studies. Most of the studies found are cohort studies and this may due to that an RCT examining wear would need to be run over at 
least five years, and longitudinal studies are difficult and expensive to run.

\section{CONCLUSION}

This review concludes that the use of larger femoral head size hasten the wear rate of the polyethylene lining of the acetabulum component. However, some studies conclude that variety of femoral head size does not have any correlation what so ever with the wear rate of the polyethylene lining of the acetabulum. More research is still needed to investigate the exact relationship between the size of femoral head and the wear rate of the polyethylene lining of the acetabular component even further before it can be used in daily clinical practice.

\section{CONFLICT OF INTEREST}

The author declares no conflicts of interest regarding the publication of this article. The author received no funding for this work.

\section{REFERENCES}

1. Rothwell A TJ, Wright M, Devane P, Tobin H, Griffin H, Henwood A, Miles K, Hobbs T, . The New Zealand Joint Registry- Twelve Year Report. 2011. Epub October 2011.

2. Beaumont R TJ, Wright M, Young E. NJR Annual Report 2011. 2011.

3. Davidson D GS, Tomkins A, Ryan P, Griffith L, Cashman K, Liu Y L, Stanford T. Hip and Knee Arthrosplasty Annual Report. 2012.

4. Garrelick G KJ, Rogmark C, Herberts P. Swedish Hip Arthrosplasty Register. 2010. Epub 1 October 2011.

5. Gopinath S CD, Guia N. Canadian Joint Replacement Registry. 2001.

6. Hip Joint- Relevant Anatomy. 28 May 2009; Available from: http://www.joint-pain-expert.net/hip-joint.html.

7. Williams $\mathrm{MH}$, Newton JN, Frankel SJ, Braddon $F_{\text {, }}$ Barclay E, Gray JA. Prevalence of total hip replacement: how much demand has been met? Journal of epidemiology and community health. 1994;48(2):188-91. Epub 1994/04/01.

8. Lachiewicz PF, Heckman DS, Soileau ES, Mangla J, Martell JM. Femoral head size and wear of highly cross-linked polyethylene at 5 to 8 years. Clinical orthopaedics and related research. 2009;467(12):3290-6. Epub 2009/08/20.

9. Livermore J, Ilstrup D, Morrey B. Effect of femoral head size on wear of the polyethylene acetabular component. The Journal of bone and joint surgery American volume. 1990;72(4):518-28. Epub 1990/04/01.
10. Geller JA, Malchau H, Bragdon C, Greene M, Harris WH, Freiberg AA. Large diameter femoral heads on highly cross-linked polyethylene: minimum 3-year results. Clinical orthopaedics and related research. 2006;447:53-9. Epub 2006/06/03.

11. Bragdon CR, Kwon YM, Geller JA, Greene ME, Freiberg AA, Harris WH, et al. Minimum 6-year followup of highly cross-linked polyethylene in THA. Clinical orthopaedics and related research. 2007;465:122-7. Epub 2007/12/20.

12. Muratoglu OK, Bragdon CR, O'Connor D, Perinchief RS, Estok DM, 2nd, Jasty M, et al. Larger diameter femoral heads used in conjunction with a highly cross-linked ultrahigh molecular weight polyethylene: a new concept. The Journal of arthroplasty. 2001;16(8 Suppl 1):24-30. Epub 2001/12/14.

13. Sayeed SA, Mont MA, Costa CR, Johnson AJ, Naziri Q, Bonutti PM, et al. Early outcomes of sequentially crosslinked thin polyethylene liners with large diameter femoral heads in total hip arthroplasty. Bulletin of the NYU hospital for joint diseases. 2011;69 Suppl 1:S90-4. Epub 2011/11/09.

14. Kluess D, Martin H, Mittelmeier W, Schmitz KP, Bader R. Influence of femoral head size on impingement, dislocation and stress distribution in total hip replacement. Medical engineering \& physics. 2007;29(4):465-71. Epub 2006/08/12.

15. C SW. Total Hip Replacement. 2012 [updated 11 November 2012; cited 201212 November]; Available from: http:// www.medicinenet.com/total_hip_replacement/article. htm.

16. Catherine Logan M. The Hip Joint: IDEA Fitness Journal; 2005.

17. 32 ed: Saunders Elsevier; 2011. Dorland's Illustrated Medical Dictionary, 32nd Edition.

18. R C. Polyethylene and Polyethylene Wear. 2012 [updated 15 May 2012]; Available from: http://www.wheelessonline. com/ortho/polyethylene_and_polyethylene_wear.

19. Moher LA, Tetzlaff J, Altman D G. Preferred Reporting Items for Systematic Reviews and Meta-Analyses: The PRISMA Statement. PLOS Medicine. July 2009.

20. Hammerberg EM, Wan Z, Dastane M, Dorr LD. Wear and range of motion of different femoral head sizes. The Journal of arthroplasty. 2010;25(6):839-43. Epub 2009/09/25.

21. Shaju KA, Hasan ST, D’Souza LG, McMahon B, Masterson EL. The 22-mm vs the 32-mm femoral head in cemented primary hip arthroplasty long-term clinical and radiological follow-up study. The Journal of arthroplasty. 2005;20(7):903-8. Epub 2005/10/19.

22. Ketut Kris Adi; KAWIYANA, I Ketut Siki. Management of acute ankle sprain: A literature review. Indonesia Journal of Biomedical Science, [S.1.], v. 10, n. 2, p. 20-26, dec. 2016. ISSN 2302-2906. Available at: <https://ijbs-udayana.org/ index.php/ijbs/article/view/130>. Date accessed: 19 Feb. 2019. doi:http://dx.doi.org/10.15562/ijbs.v10i2.130.

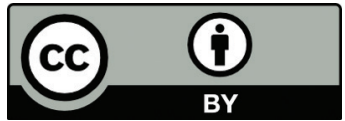

This work is licensed under a Creative Commons Attribution 